\title{
Identity Switching for Teaching Reflection - Example from Waikato Institute of Technology
}

\author{
Lihui Song \\ School of Foreign Languages, QiLu University of Technology (Shandong Academy of Sciences), China
}

\begin{abstract}
The purpose of reflective teaching is to examine teaching process and improve teacher's teaching ability. The reflective teaching course of Waikato Institute of Technology offers teachers an experience to learn a second language as fresh students. Through the process of a new foreign language learning practice, personal reflection, group discussion, personal reflective writing and teacher's guidance, the teacher trainees are hoped to get a better understanding of students' learning process, which can inspire college English teaching in China.
\end{abstract}

Index Terms - Waikato Institute of Technology, teaching reflection, learner identity

\section{INTRODUCTION}

Teachers are a crucial factor for educational development. Teaching reflection, seen as key to professional growth, plays a significant role in teachers' professional development. Cruickshank and Applegate reckon that teaching reflection is teacher's thinking about what happens in classroom teaching and thinking about alternative means to achieve goals (Bailey, Curtis \& Nunan, 2001). In teaching experience, teachers will realize some problems, through careful observation and consideration, seeking strategies and solutions to improve their teaching. Previous studies have clarified that reflective teachers tend to have a clear understanding of their teaching practice and are likely to improve their teaching (Johnson \& Golombek, 2002).

In the past four years, twelve English teachers of Qilu University of Technology have been to the TESOL Center of Waikato Institute of Technology, New Zealand. One of the most impressive subjects is Language Learning Experience and Reflections. This course combines a new foreign language learning with learning reflection to promote the future teaching career development of the teacher trainees. The method of reflection training in the course is distinctive, which focus on learning reflection instead of teaching practice reflection.

\section{The Reflection Mode IN WAikato Institute of TeChNOLOgy}

New Zealand began implementing Teacher Education Refresh Programme to promote teaching development in 2010, which is stringent in teachers' self-reflection. In the second stage of qualification review, the candidates are required to reflect on how their teaching progress is consistent with Registered Teacher Criteria. In the final stage of competency inspection, the applicants' skills in writing teaching research papers and reflection are all covered as main evaluation contents. In the view of Ministry of Education of New Zealand, reflection ability plays an essential part in the cultivation of teaching practice ability, and case analysis and the construction of personal knowledge should be attached great importance.

Then how does the TESOL Center of Waikato Institute of Technology (hereafter as Wintec) train the future teachers to do reflections? The instructor of the course demands the learners attend a new foreign language class and review their learning process from the perspective of the learners. The author summarizes this process into five steps: foreign language learning practice + personal reflection + group discussion feedback + personal reflective writing + teacher's guidance. Through the process from language learning practice to learning reflection, the learners' understanding of how a foreign language is acquired is enhanced. The cognition of this learning process will guide the learners to reflect on their teaching in the future career practice.

Doyle (1990) reckons that the process of teacher development is the process of self-reflection and self-renewal of teachers. The TESOL Center of Wintec believes that teaching reflection should not only reflect on the teaching process from the standpoint of teachers, but also should review the learning process from the perspective of students. In this way, learners can carefully examine the relevant factors which influence the learning process based on their own learning experiences. Then in the future, they can truly scrutinize the problems they meet from the perspective of learners in their teaching practice, and take the cognitive level, emotional factors, existing knowledge and culture of students into more objective and comprehensive consideration, helping them to identify problems, rectify them and prepare plans in advance.

Each complete afternoon session of the teaching reflection course of The TESOL Center is divided into two parts. In the first period, a teacher comes to teach a foreign language which the learners are unfamiliar with. The second period is the time for learning reflection. 
In the course the author participated in, the foreign language language required to learn is Korean. The author noticed that the students had quite different backgrounds in every aspect. From a cultural perspective, these students come from different countries, including New Zealand, British, South Africa, India, Egypt, Sri Lanka, Germany and China. Among other people, some are descendants of immigrants of different nationalities. As to age, we have energetic high school graduates, middle-aged females and some elderly citizens. From the motivation of learning, there are young individuals who are eager to become a competent teacher, elderly persons who want to engage in private teaching, foreign friends who are enthusiastic about learning language, and even a foreign middle-school maths teacher who comes here wanting to understand some language teaching rules in order to guide his teaching just because some foreign students appear in his class. The only similarity between them is that they have a strong desire to learning.

After giving a lecture, the Korean teacher will use the situational teaching method to help students practice in life scene simulation. For example, in the first class, the Korean teacher taught the students a few short greetings and farewells, and then before the end of the class, she organized the students to practice dialogues in pairs and groups.

In the second period, the teaching reflection instructor will come. She will firstly ask what the Korean teacher has taught in the previous class, what difficulties the learners have encountered in their own learning process, where the difficulty comes from, whether the learners have used some strategy to try to solve the problems, what strategies have been used and how about the outcome and so on.

Then the teacher will put forward a question related to other teaching aspects, guiding students to consider it seriously and discuss in groups. Group wisdom in the discussion is well implemented. Lastly, the teacher will require the learners to read some teaching literature and complete a teaching reflection writing exercise after class. Writing exercises require learners to record the impressive things that happen in their own learning process. Through writing narratives, they can dig out their personal knowledge deep down, make personal tacit knowledge explicit, and then learning reflection followed by further deeper study is promoted.

In the next class, the teacher will lead the learners to do further discussion, instructing them to describe the teaching practice in descriptive language, summarize the methods used in the language learning process, and remind the learners of considering various factors when interpreting the events, such as cultural background, age, gender, ethics, learners' personality and other related factors.

For many Chinese teachers, teaching reflection is largely ignored in daily teaching. Some teachers lack correct understanding of teaching reflection. And for some of them, teaching reflections are simply limited to the level of whether a special step is handled well or not, how the students respond, and comparing different performance in different classes. Active and in-depth thinking is missing. Teachers should enhance the teaching philosophy with a flexible and dynamic attitude, persist in learner-centered teaching practice as the core, constantly reflect on various factors in teaching and adjust the teaching methods to improve the teaching outcome. The teaching reflection of Wintec provides beneficial reference to the teaching development for Chinese college English teachers.

\section{Characteristics OF THE Reflection Mode OF WinteC}

This kind of reflection practice of learning a foreign language+learning reflection is very instructive for teachers who are engaged in college language teaching in China.

First, the focus of the course is self-reflection in learners' learning. Studies have shown that both positive and negative influences during the student period learning will have a great impact on the teaching philosophy of their future teaching career. Baileyetal instructed seven students to review the impact of their own language learning experience on their teaching philosophy and practice in an autobiographical way. It was found that on the stand of students, their learning motivation can help them overcome the teaching difficulties and shortcomings. The identity of being a student can lead them to examine their teaching ideas and practices, explore the causes, and thus more consciously improve the teaching methods (Sun Dekun, 2008).

Students' learning behaviors and results are uncontrollable and sometimes even unpredictable. The purpose of the reflection mode in Wintec is to enable learners to review learning process from a student perspective, which is undoubtedly the best way to understand students' mental activities and learning process. For many foreign language teachers, they have blurred impressions about their foreign language learning, and so this experience of foreign language learning is the most effective method. For the teacher, learning as a student, ignoring the external influencing factors, and reflecting on the whole action trajectory and learning experience of the individual in the learning process can help to find out the reasons why the students may have problems in the learning process. In this way, they can clarify learning insights and psychological processes, so that the taken-for-granted attitude in the teaching can be eliminated. Predicting the teaching activities from the perspective of students, and designing based on the students' knowledge level and cognitive level to cope with possible problems in the teaching process can lead to better teaching results.

Secondly, one of the characteristics of this course is the learners can obtain more inspirations from individual reflection and group reflection. After talking about The individual learning process, the teacher will present a question for group discussion. After one of the group members shared his/her view, the team members will have a heated discussion and give valuable feedback according to their understandings. This peer feedback is distinctive.

Kumaravadivelu (1994) proposes that teachers should implement differential teaching methods flexible to different 
teaching situations and different students. Under the guidance of such a teaching method, teacher trainees firstly will understand each individual has respective characteristics and different opinions. In the group discussion after the individual's sharing learning experience, the group members will tell their own experience to illustrate their personal views, so that everyone can understand there are different learning experiences. Only after going through group discussion feedback process and deeply reviewing various learning methods and difficulties, can the learners critically examine their teaching practice in the future career, and consciously adjust the teaching strategies and integrate learning with teaching.

For example, in the first lesson, the topic for the learners to discuss is: among all your teachers, who impresses you most and why. A seemingly common question has sparked heated discussions. After group discussion, each group recommended a representative to share ideas. The teacher listed all the quality mentioned on the blackboard. She analyzed the characteristics of the outstanding teachers and guided the students to think about how to become a good teacher loved by the students. In fact, during the discussion and sharing process, when the peers gave feedback to speakers, they also shared some negative examples to avoid such wrong doings in future. Such group reflection will be more extensive and deeper than independent self-reflection, which can promote learners to develop a good habit of self-reflection from different aspects, examining themselves and identifying gaps to consciously correct their deficiencies.

Thirdly, one of the requirements of this course is that words of reflections must be written down. The effect of deep learning will not be achieved if learners just share something in words or think about it. Encouraging learners to note down what they have reviewed and record the learning experience and observations will guide them to think further. Such a writing is named as reflective journal.

Reflection is an essential part for the professional development of teachers. Wallace (1991) believes that teacher development means change and lack of reflection will be difficult to achieve effective change. This shows the significance of reflection in teacher development. Therefore, facilitating teaching reflection has become indispensable.

During recent years, many researches have proven that teachers who employ reflective journals are more likely to become reflective practitioners. Specialized literature indicates writing reflective diaries is an effective tool for teaching professional training. As an important part of pre-service teaching practice, reflective diaries help organize the analysis and summary of pedagogical practice. The doings at Wintec teaching lead to the teacher candidates' identifying students' needs, learning motivation, the level of previous language acquisitions. Teachers engaging in pedagogical reflection will think over puzzles, understand more about the theoretical basis and strive to foster consistency between them.

In the initial writing, many learners will feel that they do not know what to write after describing the learning incidents in a simple way. The experiences cannot be deeply interpreted if they could not make explanations. The teacher asks the learners to concentrate on one point each time and manage to search for more information in educational literature, analyze it in depth, probe into it and find a way to solve the puzzle. The gap between educational theory and classroom practice will be bridged by such reflections on actions and classroom practices.

At the beginning of next class, the teacher will organize a class discussion, give instructions and summary. Then in the following session, each student should examine whether the solution is effective in the learning practice and whether the individual learning has been improved. Gradually, a learner will find the best solution to his/her problem. Such reflection and guidance does not blindly follow some profound teaching theory, instead, encourage learners to offer their own theoretical insights in practice and take corresponding actions to solve problems, truly making reflection an effective way of teaching development. When these learning experiences are accumulated enough to form individual learning beliefs, they will become internal framework to guide future teaching.

\section{ENLightenMent to Chinese College ENGLish teACHING}

The background of the students at Wintec is more complicated than their Chinese peers. In China, the students in the same class have similar cultural backgrounds, ages, similar previous high school learning and living patterns. The differences among our Chinese students are the individual's learning habits and family background. But cultural background, age and motivation of the students at Wintec are very different. Therefore, it will be easier for us to improve teaching by reviewing our learning and teaching experience and summarizing students' puzzles.

First, learning reflection and teaching reflection should be implemented simultaneously. In Wintec, the teacher of the reflection course will guide the learners to carry out learning reflection, reviewing the learning difficulties and the methods used to acquire a new language after the Korean learning period. This training is designed to give the learners a better understanding of their learning strategies and to reflect on how such learning strategies can help individuals solve specific learning problems. Because, in many cases, learning failure results from ineffective strategy. Thinking about the differences between invalid and effective strategies can motivate individuals to work hard to find an effective learning method.

Our students vary in learning level and skills they need to improve in College English. Therefore, teachers can assist students to improve their learning through reflecting on their study habits and individual learner characteristics. At the same time, teachers should also review their own teaching after class. Collecting the information of students' learning difficulties and compare them with teaching plan, adjusting teaching through timely communication with students after 
class. The cultivation of both students' learning reflection and teacher's teaching reflection are synchronized, which will be helpful for guiding teachers to maintain correct orientation in teaching. Reflecting on teaching methods and teaching outcome, understanding and discovering problems in teaching, and timely adjusting teaching content and progress will result in the improvement of teaching.

Secondly, the difference in beliefs between teachers and students in the course will lead to different perspectives on the course. Learners are not allowed to evaluate the Korean teacher's teaching in the reflection course, and they can only reflect on their own learning process. However, the students will inevitably discuss the learning experience after the class. Because the Korean language teacher is Asian and the students come from all over the world, people in different countries have great differences in the cognitive pattern of knowledge learning, so the difference in belief between teachers and learners will cause some problems. The teacher does not explain her teaching philosophy to the students, the students from different countries will make assumptions from different aspects. When the teacher's classroom practice does not correspond to the students' learning expectation, the students will be a little disappointed. Therefore, it is very important to explain teacher's teaching philosophy and methods to students before beginning a new course with a group of new students.

It is no wonder why our students often have negative reactions when they have to participate in listening and speaking training in college English. Many students have formed a stereotype that English learning should focus on vocabulary, grammar and reading and they think that they cannot learn from other students in listening and speaking training, especially in group discussion, which is a waste of time in their eyes.

This is because in the middle-school English education is usually a training paying more attention to reading and writing. After entering the university, some students' expectation for English class is continuation of full-time teaching of vocabulary and reading. Such difference in students' and teachers' beliefs will lead to the underestimation of teaching activities.

Similarly, the different beliefs in the curriculum between teachers will also cause different teaching implementation. For example, some teachers believe that English learning should be based on the students' learning needs, such as passing through CET-4. As a result, examination-oriented teaching is the main target of such teachers. Some other teachers believe that college English should be targeted at developing students' communicative competence. Then the teaching will not rely too much on teaching materials, but on the cultivation of authentic and reliable corpus, multiculturalism and students' communicative competence. Different teachers' beliefs in teaching objectives, teaching plans and teaching assessments will lead to different classroom practices. Therefore, the ideas of the course should be clearly illustrated.

Thirdly, the ability to control class practice in College English teaching is very important. In the reflection course of Wintec, the teacher is confronted with a variety of unforeseen problems in the face of complex student backgrounds, which requires teachers' excellent capability of controlling classroom activities and handling puzzles. Similarly, nowadays in our college English teaching, teachers will also face a lot of unpredictable problems due to students' large amount of information resources through various channels, which has higher requirements for the teachers. Teachers should keep abreast of the changing learning characteristics and psychological state of the students, learn more, and keep up with the pace of development of the times. In the information age, teachers should not only smoothly connect with students in the knowledge system, but also pay attention to the change of learning beliefs of new generation students.

Bialystok (1978) believes that learner beliefs have a decisive influence on their learning and can influence students' learning motivation, learning expectations, classroom behavior and learning strategies. Differences in learning beliefs can cause differences in their performance in all aspects. For example, students of different cultural backgrounds have different beliefs about classroom behavior. Asian students often think that it is impolite to interrupt teacher's lectures in class. Therefore, in a classroom of international students, many Asian students often cannot accept others' timely questions because they think this will influence teacher's teaching fluency. On the other hand, learning beliefs of different learners may also be related to cognitive style and some personal factors. If the teacher can understand students' learning style as much as possible and give them instructions based on their different learning style, the students can better improve their learning.

\section{CONCLUSION}

In addition to classroom learning, the learners of Wintec will also enter the classroom to observe class and do some teaching under the uniform arrangement of the institute. In this way, they can benefit from both the student's learning perspective and the guidance of professional teachers. Only when they learn more, practice teaching and then know the difficulties, will they be able to teach and develop their future career.

One reason why teaching reflection in college English teaching is difficult to make great progress is some teachers do not have the habit of reviewing teaching practice after class. On the other hand, teachers only reflect on problems from their perspectives and could not switch their identity and think over the problems from the perspective of students. Finally, some teachers think that the teaching reflection of each lesson is difficult to have a unified point, so there is not much significance. But in fact, the focus of the second lesson will always follow the reflection of the first lesson. Through the connecting of related points in each lesson, the independent event fragments can get the value and meaning 
of interpretation. Teaching reflection is inseparable from the teaching practice and learning experience as well. It is precisely in practice that the thinking is done to promote the growth of teachers.

Wallace once put forward three models of teacher learning. The first one is applied science model, suggesting student teachers learn to be teachers by applying the knowledge learned into practice. The second kind is apprentices model, which proposes imitating an expert teacher. These two methods, corresponding to teacher training, are most widely used in the normal universities in China. In Wintec, the third type, reflective model is practiced with concentrating on teacher development while acquiring related theories and observing excellent teachers' class. Their education in teacher development embodies Shulman's notion that teaching is an involvement of both action and the thinking that underlies it. It provides a model for how teachers learn to teach through their own reflection (Shulman, 1986).

Wintec's teaching reflection practice helps learners combine learning with teaching, summing up the learning process, actively looking for ways to solve the puzzle as learners, and accumulate learning experience to achieve the maximum effective teaching in future teaching. Everything begins with learning experience. By adopting such a reflective teaching pedagogy, educational inspirations can be imparted to teacher trainees and teachers. If our college English teachers can start reflecting on teaching from learning reflection, and teach students to reflect on their own learning and communicate effectively, it will undoubtedly make our college English teaching arrive at a new level.

\section{REFERENCES}

[1] Bailey, K., Curtis, A. \& Nunan, D. (2001). Pursuing professional development: the self as source. Boston, MA: Heinle \& Heinle.

[2] Bialystok, E. (1978). A Theoretical Model of Second Language Learning. Modern Language Journal, 28, 69-83.

[3] Doyle, W. (1990). Themes in Teacher Education Research. In W. R. Houston, M. Haberman, \& J. Sikula (Eds.), Handbook of Research on Teacher Education. New York: Macmillan Pub. Co., 3-24.

[4] Johnson, K. E. \& P. B. Golombek (eds.) (2002). Teachers' narrative inquiry as professional development. Cambridge: Cambridge University Press.

[5] Kumaravadivelu, B. (1994). The Postmethod Condition: Emerging Strategies for Second/Foreign Language Teaching. TESOL Quarterly, 28, 27-48.

[6] Shulman, L. S. (1986). Those who understand: Knowledge growth in teaching. Educational Researcher, 15, 4-14.

[7] Sun Dekun. (2008). Teacher cognition research and teacher development. Chinese Teaching in the World, 3, 74-86.

[8] Wallace, M.J. (1991). Training Foreign Language Teachers: A Reflective Approach. Cambridge: Cambridge University Press.

Lihui Song was born in Yantai, China in 1979. She received her master degree in English Literature from Shandong University, China in 2009.

She is currently an associate professor in the School of Foreign Languages, QiLu University of Technology (Shandong Academy of Sciences), Jinan, China. Her research interests include English teaching and English literature. 